Technical Report No. 32-404

\title{
The Electric Space Cruiser for High-Energy Missions
}

\author{
Robert J. Beale
}

Evelyn W. Speiser

James R. Womack

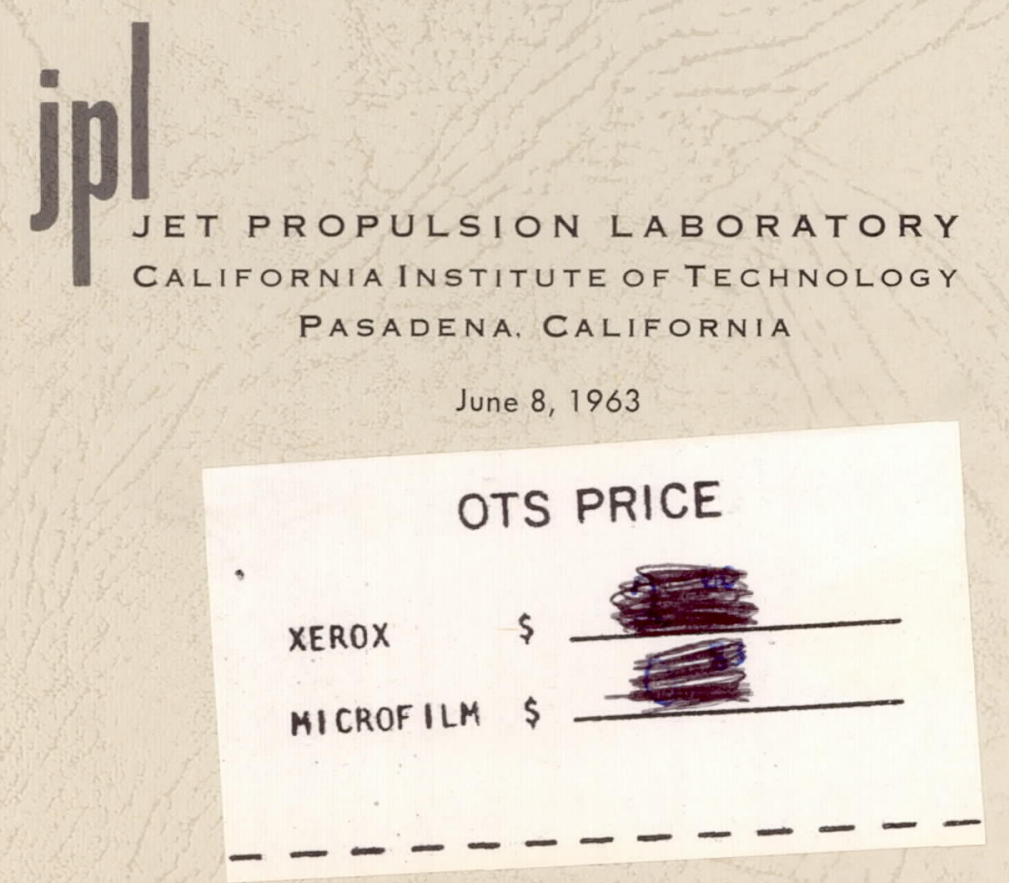


Copyright (C) 1963

Jet Propulsion Laboratory

California Institute of Technology

Prepared Under Contract No. NAS 7-100

National Aeronautics \& Space Administration 


\section{CONTENTS}

I. Introduction . . . . . . . . . . . . . . . . . . . . 1

II. High-Energy Missions . . . . . . . . . . . . . . . . . . . . . . . . . 2

A. General Considerations . . . . . . . . . . . . . . . . . . . . 2

B. Mission Ca ability of the Space Cruiser . . . . . . . . . . . . . 2

III. Description of the Space Cruiser . . . . . . . . . . . . . . . . 3

A. Configuration . . . . . . . . . . . . . . . . . . . . . 3

B. Mode of Oeration . . . . . . . . . . . . . . . . . . . . . . 7

C. Systems Considerations $\quad$. . . . . . . . . . . . . . . . . . . . . 8

IV. Propulsion System Parametric Studies . . . . . . . . . . . 11

v. Conclusions . . . . . . . . . . . . . . . . . . . 13

References . . . . . . . . . . . . . . 14

\section{TABLES}

1. Space cruiser missions . . . . . . . . . . . . . . . . . . . 2

2. Space cruiser weight summary for Jupiter orbiter mission . . . . . . 6

FIGURES

1. Perspective view of space cruiser . . . . . . . . . . . . . . . . . . . 4

2. Schematic of 500-kwe nuclear powerplant . . . . . . . . . . . . 5

3. Power distribution diagram . . . . . . . . . . . . . . . . . . . . 5

4. Jupiter orbiter mission trajectory . . . . . . . . . . . . . . . . . . 7

5. Power profile for Jupiter orbiter mission . . . . . . . . . . . . . 8

6. Micrometeoroid flux intensity profile for a Jupiter orbiter mission . . . 9

7. Propulsion system weight vs. gross electrical power . . . . . . . . 11

8. Propulsion system specific weight vs. gross electrical power . . . . . 12

9. Net payload vs gross electrical power . . . . . . . . . . . . . 12 



\begin{abstract}
A basic spacecraft capable of significant, unmanned exploration of the entire Solar System can be achieved by the use of a modest nuclear-electric propulsion system employing a Saturn 1-B booster chain. Within a L-yr flight time, the spacecraft would be able to explore the near-Exirth region of the Solar System. With an ultimate 2-yr propulsion syster 1 lifetime goal, the spacecraft would be able to orbit Jupiter and to probe the remainder of the Solar System.

Basic system requirements for this type of vehicle are thrust devices efficient in the specific impulse range of $6000-12,000 \mathrm{sec}$, a nuclear turboelectric powerplant of $500 \mathrm{kwe}$, weighing about $14 \mathrm{lb} / \mathrm{kw}$, and a total spacecraf weight of $20,000 \mathrm{lb}$.

A brief systems description of the spacecraft is presented. For discussion purposes a Jupiter orbiter mission is used as an example. The modes of operation for the spacecraft are reviewed and a summary of major subsystem weights is shown. Other study areas explored and reported indicate a typical power profile for the mission, micrometeoroid armor requirements, the effect of nuclear shielding tradeoffs, and the major factors determining the selection of the optimum power level.
\end{abstract}


JPL TECHNICAL REPORT NO. 32-404

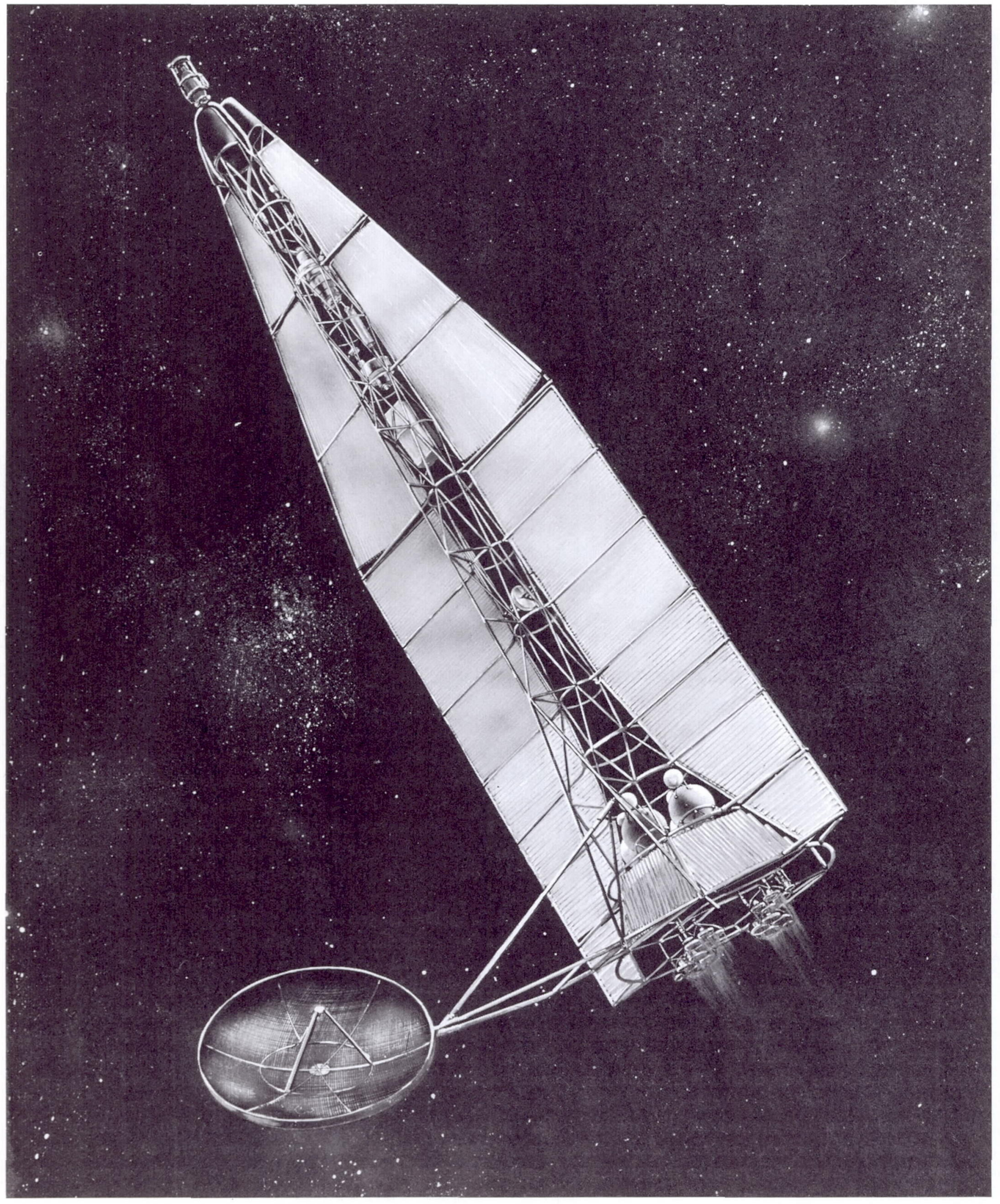




\section{INTRODUCTION}

A number of studies in recent years have shown the wide range of applications for nuclear-electric propulsion systems. Many of these studies (Ref. 1 and 2) have investigated specific mission applications with particular booster systems, while others (Ref. 3,4 , and 5 ) have taken a more parametric approach. The power levels investigated have ranged from a few kilowatts up to many megawatts; applications have included orimary propulsion for both unmanned and manned flights, as well as auxiliary propulsion for satellite attitude control and stationkeeping functions. Although most of the studies have considered employing the nuclear-electric systems to their full advantage, some have chiefly sought applications for specific existing units and in so doing have proposed such significant compromises that there seemed little advantage in employing the nuclear-e ectric system at all.

From a review of these various studies, the conclusion can be drawn, however, that it is frossible to select a nuclear-electric system which, if prop rrly matched to the booster system and to the dictates of the mission or missions, can out-perform any other systems presently conceived in the performance of high-energy missions.

To determine the first really practical and advantageous application of nuclear-electric propulsion for unmanned planetary exploration the Advanced Propulsion Engineering Section of the Jet Propul:ion Laboratory has recently completed a comprehensive study of a nuclearelectric system.
The gross requirements considered in the selection of the propulsion-system design were the following:

1. The propulsion system should be of reasonable size from both a power level and dimensional standpoint (a power level range of 300 kwe to 1 Mwe was considered to define the outer limits of this particular requirement).

2. The system should be compatible with an existing or firmly scheduled booster. This compatibility should consider a reasonable dimensional and schedule match between the electrically-propelled spacecraft and the selected booster.

3. The propulsion concept should be basically simple and potentially reliable.

4. The resulting propulsion system design should have sufficient flexibility to allow employment for a wide variety of planetary and interplanetary missions over an extended calendar time period (nominally the decade from 1970-1980).

The resulting concept, termed the "space cruiser" is described in this Report. In addition, some of the tradeoff capabilities for the system designer attempting to employ such a system, as well as some of the major problem areas, are discussed. 


\section{HIGH-ENERGY MISSIONS}

\section{A. General Considerations}

The necessary prelude to any manned flights throughout the Solar System is a thorough exploration of planetary and interplanetary space. The unique suitability of a nuclear-electric space cruiser for this exploration and, in particular, for high-energy missions has long been apparent. Unlike chemical or nuclear-rocket propelled spacecraft, the payload of an electric spacecraft does not drastically and irrevocably decrease as higher and higher energy missions are attempted. It is, therefore, feasible to design a single, relatively modest spacecraft which, with a nuclear-electric propulsion system, is capable of reaching any part of the solar system. The space cruiser should provide the first capability of achieving any of the more difficult deep-space objectives.

For initial exploration, it is not necessary to provide an extremely large net payload; an acceptable size for early missions is of the order of 4000-6000 lb (Ref. 4), of which about $10 \%$ is the actual scientific instrument weight. The space cruiser described here is capable of delivering these payloads utilizing the Saturn 1-B booster, which is already well under development.

The tradeoff between payload and flight time, for a low-thrust, high specific impulse, propulsion system, can be profitably made over such wide ranges that it is possible to maintain almost a constant payload to any destination in the solar system.

\section{B. Mission Capability of the Space Cruiser}

For this study the initial spacecraft weight orbited by a Saturn $1-B$ was assumed to be $20,000 \mathrm{lb}$ plus $800 \mathrm{lb}$ of power plant start-up equipment. This latter equipment would be separated from the spacecraft following start-up. The performance capability of the Saturn 1-B was also assumed to allow for a protective aerodynamic shroud which would be jettisoned during the early boost flight. The gross power level of the nuclear-turboelectric powerplant for this spacecraft was selected at $500 \mathrm{kwe}$, for reasons which are detailed in Ref. 3 and Section IV. The resulting system analysis was directed toward meeting the requirements of a Jupiter orbiter mission. This is one of the more difficult planetary missions and was considered to be a good model for the study. However, with little change in design, save for increased thermal protection for missions toward the Sun, the space cruiser could deliver its 4000-6000-lb payload for a range of missions including solar probes to $0.1 \mathrm{AU}$, Mercury orbiters, Mars orbiters, Venus orbiters and 30-deg out-of-the-ecliptic probes, all in less than 300 days total flight time.

Table 1 lists several space cruiser missions. The term "net payload" includes scientific instrumentation, guidance and control, telecommunications, and other payloadoriented equipment. The powerplant itself is not included in the net payload, although in most cases it is still operating and can be used to power scientific experiments and data-transmitting equipment for the duration of the experimental phase of the mission.

Table 1. Space cruiser missions

\begin{tabular}{|l|c|c|c|}
\hline \multicolumn{1}{|c|}{ Mission } & $\begin{array}{c}\text { Flight } \\
\text { time, } \\
\text { days }\end{array}$ & $\begin{array}{c}\text { Terminal } \\
\text { mass, } \\
\text { lb }\end{array}$ & $\begin{array}{c}\text { Net } \\
\text { payload, } \\
\text { lb }\end{array}$ \\
\hline Solar probe (to 0.1 AU) & 300 & 14,400 & 5250 \\
Mercury orbiter & 300 & 14,550 & 5400 \\
Mors or Venus orbiter & 225 & 14,500 & 5350 \\
Jupiter orbiter & 750 & 14,250 & 5100 \\
Saturn probe & 700 & 14,550 & 5400 \\
Pluto probe & 1400 & 12,400 & 3250 \\
30-deg & 230 & 14,000 & 4850 \\
Out-of-the-ecliptic & 620 & 13,900 & 4750 \\
Mars round trip & & & \\
(48-day wait) & 125 & 14,660 & 5510 \\
Venus probe & &
\end{tabular}

It is interesting to note, in Table 1 , that a $10,000-\mathrm{hr}$ system lifetime is more than sufficient for exploration of the region of space extending from the Sun to beyond the orbit of Mars. This may be regarded as the region in which the initial flights of the space cruiser will most probably occur. One of the more likely early missions is the 30-deg out-of-the-ecliptic probe, which is extremely difficult to perform with any propulsion system other than nuclear-electric. This particular mission has the advantages of requiring no launch window, no elaborate thermal control and a relatively short propulsion time.

Although it is desirable, from a developmental viewpoint, to schedule the first few space cruiser missions for a lifetime of $10,000 \mathrm{hr}$ or less, a lifetime of $20,000 \mathrm{hr}$ 
should be the design goal for the extire spacecraft system. It is with this duration capability that such advanced missions as a Jupiter orbiter, Saturn probe, and Mars or Venus round trips can be accomplisl ed.

The Venus probe mission listed last in Table 1 is included chiefly for comparison purposes. Its 125-day flight time is comparable to that of chemical systems, such as Mariner, although the payload is, of course, considerably larger. Probably by the time the space cruiser is flown, such a mission will no longer be necessary. However, it is interesting to note that even for such a relatively close target as Venus, a nuclear-electric system can be made competitive in flight time with a high-thrust system.

\section{DESCRIPTION OF THE SPACE CRUISER}

\section{A. Configuration}

Figure 1 (also the frontispiece) shows a perspective of the 500-kwe nuclear-electric propulsion space-cruiser configuration for the Jupiter orbiter mis:ion. This configuration may also be considered typical of those spacecraft which could be utilized to perform any of the missions described in Table 1. Changes in configuration from mission to mission would be concerned primarily with details of the scientific payload.

Electrical power required for the electric thrust motor operation and for other spacecraft systems is derived from the nuclear-turboalternator powerplant, which is located in the front half of the space cruiser illustrated in Fig. 1 and shown schematically in Fig. 2. At the forward end (Fig. I) is an integrally packaged, nuclear reactor-boiler unit which supplies the thermal energy to the power conversion unit shown pcsitioned in the central body structure directly behind the nuclear shield. Angular momentum caused by the rutation of the power conversion turboalternator is counterbalanced by a momentum transfer wheel located directly behind the alternator.

Electrical power generated by the alternator is delivered to the power conditioning equipment which is mounted within the central structure behind the momentum transfer wheel. In the conditioning equipment the power is transformed and rectified to meet the requirements of the ion motor and other spacecraft systems.
To minimize the losses caused by the transmission of relatively low voltage, high current power from the generator, the transformers are located in close proximity to the generator. This allows for the transmission of the majority of the power, which is required by the ion motors, at high voltage and low current. For this reason the transformers are shown directly behind the momentum transfer wheel.

It is estimated that the transformers may be able to operate at a sufficiently high temperature $\left(500^{\circ} \mathrm{F}\right)$ so as to be self-cooled by radiation. The rectification equipment is expected to operate at lower temperatures and would necessarily be located within the electronic packages at the aft end of the space cruiser. Figure 3 is a block diagram showing how the power generated by the nuclear system would be utilized.

The rejected heat from the thermal-to-electrical power conversion cycle is radiated to space by two primary condensing radiator assemblies of trapezoidal shape. These are shown extending from each side of the central structure (Fig. 1). The radiator design is a mass-optimized tube-fin geometry utilizing a constant temperature gradient fin configuration, and is sized for an approximately $17 \%$ efficient power conversion cycle. The heat rejection occurs at an average radiating temperature of $1200^{\circ} \mathrm{F}$. The radiator tube layout illustrated in Fig. 1 shows one possible approach to maintaining constant length for all 


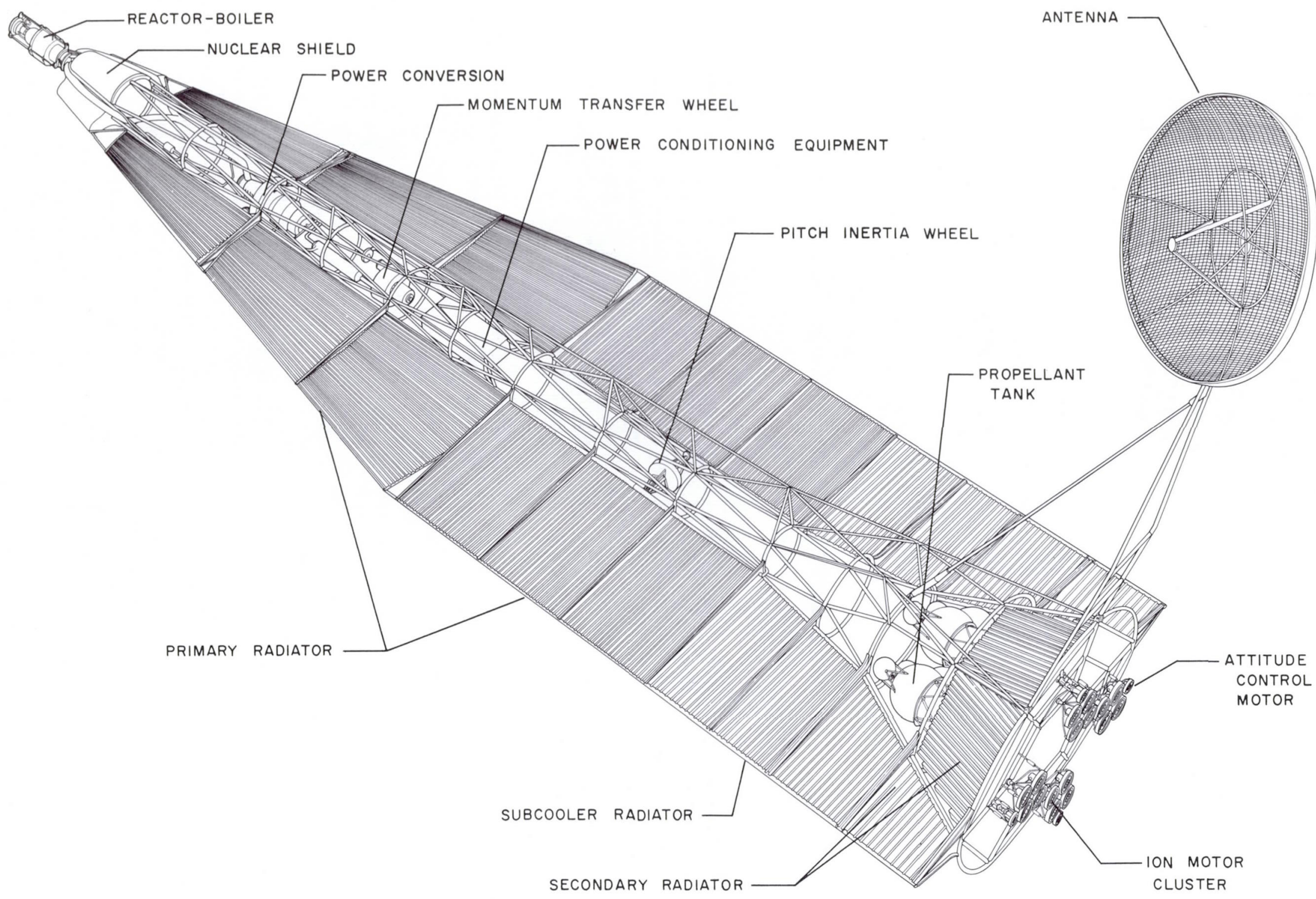




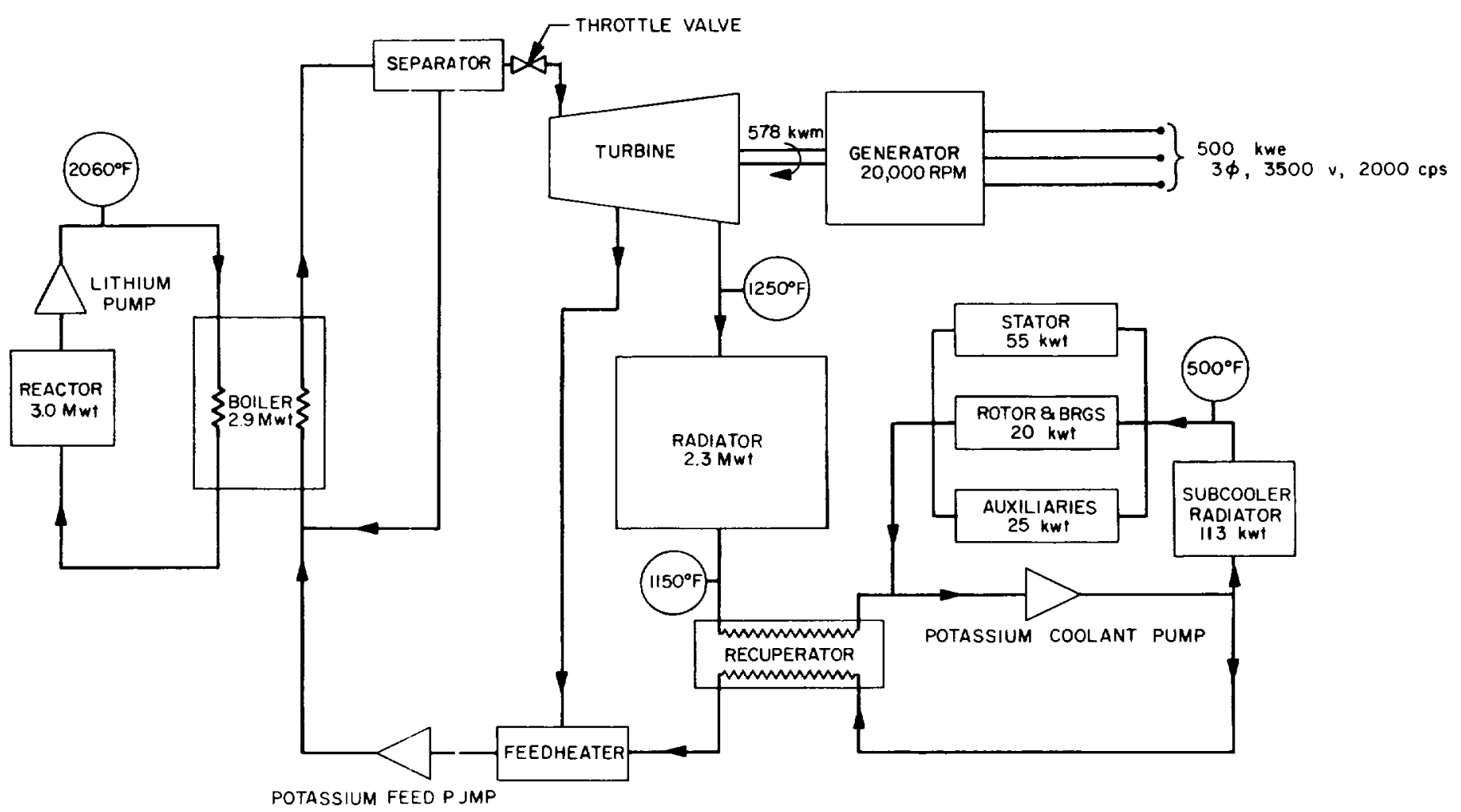

Fiyl. 2. Schematic of 500-kwe nuclear powerplant

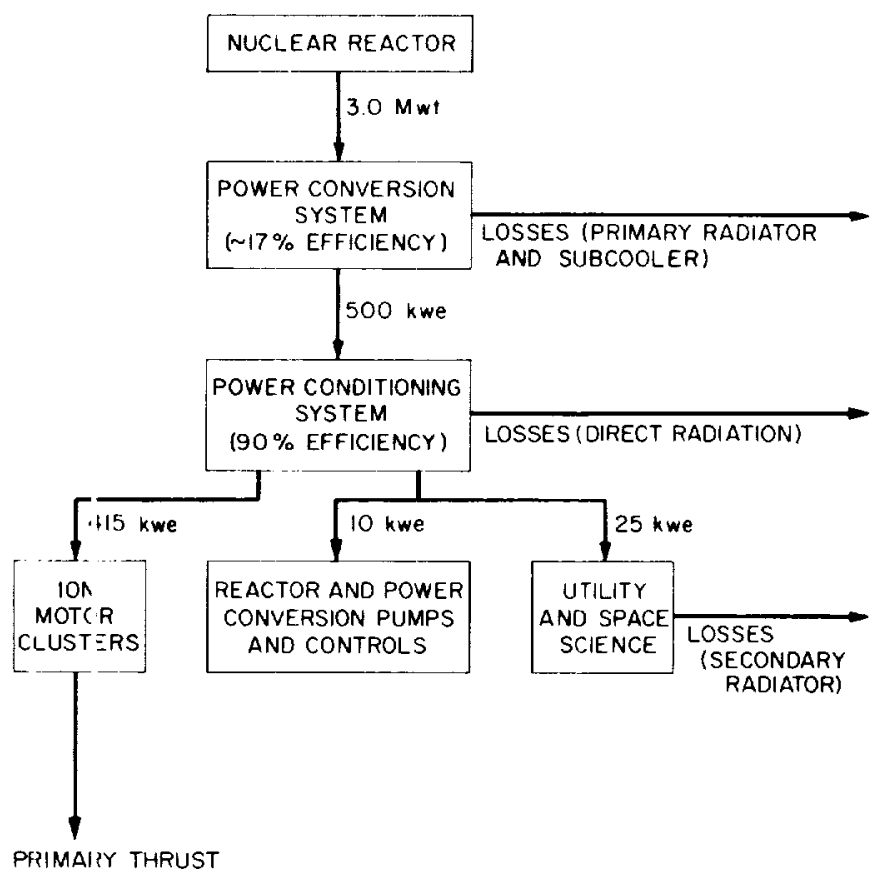

Fig. 3. Power distribution diagram 
the condensing tubes while meeting the dimensional constraints imposed by the irregular shape of the radiator panels. Total radiating area is about $1000 \mathrm{ft}^{2}$

Directly behind the primary radiator assemblies are noncondensing subcoolers, required for generator and bearing cooling. These subcoolers reject heat at around $500^{\circ} \mathrm{F}$ and have a total heat-rejection area of approximately $340 \mathrm{ft} . "$

The orientation of the space cruiser would be such that both the primary and subcooler radiator panels would lie in the plane of the ecliptic in order to minimize the effects of solar heat load.

The nuclear radiation shield, located between the reactor-boiler and the power-conversion unit, was sized so that at the payload area, located at the rear of the space cruiser, the fast neutron and gamma doses, integrated over $20,000 \mathrm{hr}$, would not exceed $10^{13} \mathrm{n} / \mathrm{cm}^{2}$ and $10^{9} \mathrm{ergs} / \mathrm{gm}(\mathrm{C})$, respectively. The geometric shape of the shield is such that the majority of the space cruiser systems (including the radiator panels, but excluding the antenna dish, a portion of the antenna boom, and plumbing from the boiler to the turbine) lie in the shadow of the solid cone angle of the shield, thereby reducing the dose at the payload caused by scattered neutrons.

Mounted at the aft end of the space cruiser in a geometrically symmetrical arrangement about the spacecraft roll axis are four gimballed ion motor clusters, each cluster consisting of four ion motor modules. These units would provide the propulsive thrust and, by gimballing of appropriate clusters, would allow gross corrections in pitch, yaw, and roll attitude.

Small corrections in spacecraft attitude would probably be handled adequately by inertia wheels. One such wheel is shown near the middle of the space cruiser in the central structure. This particular wheel would be used to make small corrections in pitch. Yaw and roll control wheels would be located in the spacecraft payload region at the aft end of the space cruiser. If the inertia wheels become saturated, or if major changes in attitude should become necessary, then the gimballed ion motor clusters would be called upon to act.

During the coast period of the trajectory, the inertia wheels could again provide small corrections in spacecraft attitude. However, major changes in attitude during this period would be accomplished by four additional small, secondary, gimballed ion motor modules, one mod- ule mounted outside the periphery of each primary thrust ion motor cluster.

The electronic packages and scientific instruments are shown directly forward of the ion motor clusters. If active cooling should be required by these components, low temperature $\left(\sim 200^{\circ} \mathbf{F}\right)$ heat rejection radiators surrounding the hexagonal structure of the payload section and the panels extending radially from each side of the payload section could be used. Mounted above the main body of the space cruiser is a $15-\mathrm{ft} D$ steerable communications antenna. During boost, this antenna would be folded against the main body of the space cruiser.

Forward of the electronic packages are four ion motor propellant tanks and their respective pressurization tanks. This arrangement provides for each ion motor cluster a propellant feed system independent from the other ion motor clusters. The propellant tanks shown are sized for cesium.

Table 2 is a weight summary of the major systems of the spacecraft.

Table 2. Space cruiser weight summary for Jupiter orbiter mission

\begin{tabular}{|c|c|}
\hline System & Weight, Ib \\
\hline Propulsion system (less lankage and propellant) & 9150 \\
\hline Reactor-boiler & 1200 \\
\hline Nuclear shield & 2380 \\
\hline Turbine & 200 \\
\hline Generator & 900 \\
\hline Primary radiator & 1820 \\
\hline Subcooler radiator & 450 \\
\hline $\begin{array}{l}\text { Pumps, feedheater, recuperator, piping and } \\
\text { separator }\end{array}$ & 200 \\
\hline $\begin{array}{l}\text { Startup equipment (includes only that equipment } \\
\text { which must remain with spacecraft through- } \\
\text { out mission) }\end{array}$ & 700 \\
\hline Power conditioning & 800 \\
\hline Ion motors & 500 \\
\hline Propellant & 5750 \\
\hline Net Payload & 5100 \\
\hline Communications & 600 \\
\hline Antenna dish & 100 \\
\hline Guidance and control & 1000 \\
\hline Structure, cabling, tankage and thermal control & 2400 \\
\hline Engineering and scientific instrumentation & 1000 \\
\hline INITIAL MASS IN EARTH ORBIT & 20,000 \\
\hline
\end{tabular}




\section{B. Mode of Operation}

Of the many sequences of operations associated with a nuclear-electric spacecraft, one of the most critical probably will be the nuclear pow rplant startup. The type of startup considered for the space cruiser is a combination ground-orbital startup. The primary system (nuclear reactor) and the seconclary system (power conversion unit) will be filled with their coolant and working fluid, respectively. Prior to launch, romponent heatup is initiated and continues until both the primary and secondary systems are at approximately $1000^{\circ} \mathrm{F}$. This heatup might be accomplished by circuluting heated argon within the shroud or through the use of electrical resistance heating. The nuclear reactor is not started at any time during this procedure.

Once the systems are at the designated temperature, the booster (a Saturn 1-B in this ase) lifts the space cruiser into a predetermined circular Earth orbit. The shroud would be jettisoned as soon as the space cruiser was out of the atmosphere. Heat losses from the preheated components could be controlled by employing a "balloon" thermal-radiation shield. The argon atmosphere maintained within the shroud during the launch-to-Earthorbit phase is used to deploy the the mal shield and then vented to space. Such a shield would typically maintain allowable startup temperatures with no additional heat input for at least $3 \mathrm{hr}$ following latnch. For this study, it is estimated that the space cruiser would be placed into a 1000 -nm Earth orbit; it is asst med that this would satisfy all the safety requirements for nuclear reactor operation in orbit.

Once the orbit has been established, the space cruiser is activated. The reactor startup $s$ quence is initiated with power required for this operation being supplied by either batteries or by power from the still-attached booster stage. Startup of the power conversion system is begun only after the reactor coolan- has been raised to a preselected temperature. After the reactor and power conversion system are operating, tl e "balloon" thermal shield is jettisoned, the space cruise" separated from the booster, and the ion motors startec. The space cruiser now begins the first portion of the Earth orbit-Jupiter orbit trajectory.

In this first full-power flight peric $d$, the space cruiser spirals out from the initial Earth orbit until Earth escape energy is reached. For the Jupiter rbiter mission, this escape spiral requires approximately 108 days at constant tangential thrust.
Following Earth escape is the heliocentric transfer of the vehicle to the vicinity of Jupiter. This transfer will be the optimum constant-thrust-plus-coast type, where the thrust level is constant during powered flight with the thrust angle varying in an optimized manner (Ref. 6). Figure 4 illustrates the behavior of the thrust vector during a typical transfer to Jupiter.

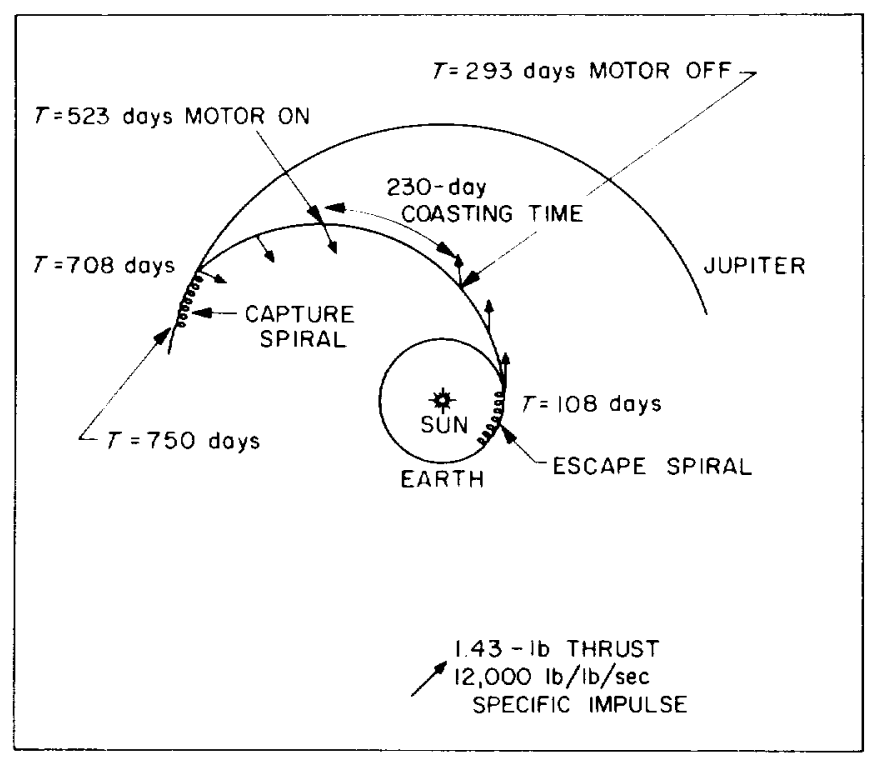

Fig. 4. Jupiter orbiter mission trajectory

The first portion of this heliocentric transfer lasts about 185 days. Following this flight period is a coast period of 230 days. During this period, the powerplant operates at a reduced power, in this case 125 kwe. This power would be used primarily for the attitude control system, communication, and scientific instruments.

Following the coast period is a second heliocentric powered period of 185 days. A final 42 days of constant tangential thrust places the space cruiser in a close elliptical orbit around Jupiter.

The total time for the flight is thus 750 days, of which 520 days are spent under full thrust. After establishing a Jupiter orbit, at least 83 days would be available for scientific exploration with power supplied by the powerplant. Figure 5 presents, in summary form, the power profile for the described mission.

The final orbit established around Jupiter was chosen to have a semimajor axis of 1.5 million nautical miles. If desired, this orbit could be highly elliptical, which 


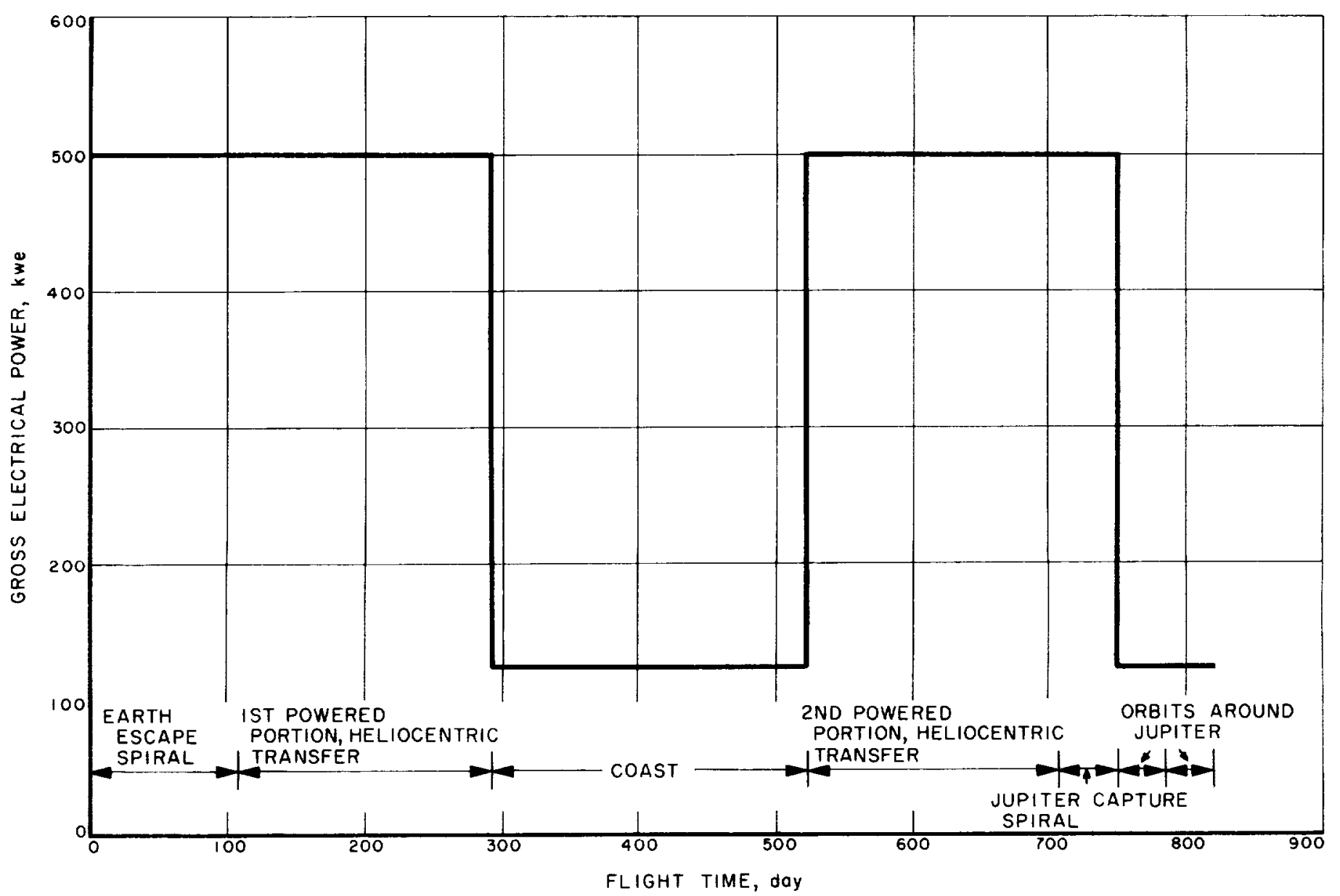

Fig. 5. Power profile for Jupiter orbiter mission

would permit a much closer approach at periapse. An eccentricity of 0.9 , for instance, gives a distance of closest approach to Jupiter's surface of about $112,000 \mathrm{~nm}$. The period of the Jupiter orbit will be about a month, permitting more than two complete orbits within the powerplant lifetime of $20,000 \mathrm{hr}$.

\section{Systems Considerations}

Integration of the powerplant into the spacecraft results in a number of interesting systems considerations. One of major interest is the protection of the radiator tubes from micrometeoroids.

Armoring of the radiator tubes is considered, at present, to be the most feasible means of protection from micrometeorite puncture. An estimate of the flux of micrometeoroids which the radiators would experience during a Jupiter orbiter mission is shown in Fig. 6. The expected micrometeoroid intensity relative to near-Earth, which is portrayed as a function of flight time, was obtained from a detailed study of micrometeoroid flux models by J. J. Volkoff (Ref. 7). ${ }^{1}$

By an integration process, described by Volkoff, the armor requirement relative to that designed for a nearEarth orbital mission can be computed. For the space cruiser primary radiator, it appears that an armor thickness of 0.085 in. of titanium will give a greater than $95 \%$ probability of no puncture. Considerably less armor will be required for the subcooler tubes to obtain the same probability. If beryllium were used in place of the titanium for the primary radiator armor and fin material, a thickness of about $0.120 \mathrm{in}$. would be reguired for the same probability of no puncture. In spite of the greater thickness, the total radiator weight would be less. The radiator weights shown in Table 2 consider the use of

${ }^{1}$ Although the mission time selected for Volkoff's study was slightly shorter than the 750 days used in this Report, the estimate of armor thickness for the two cases is essentially the same. 


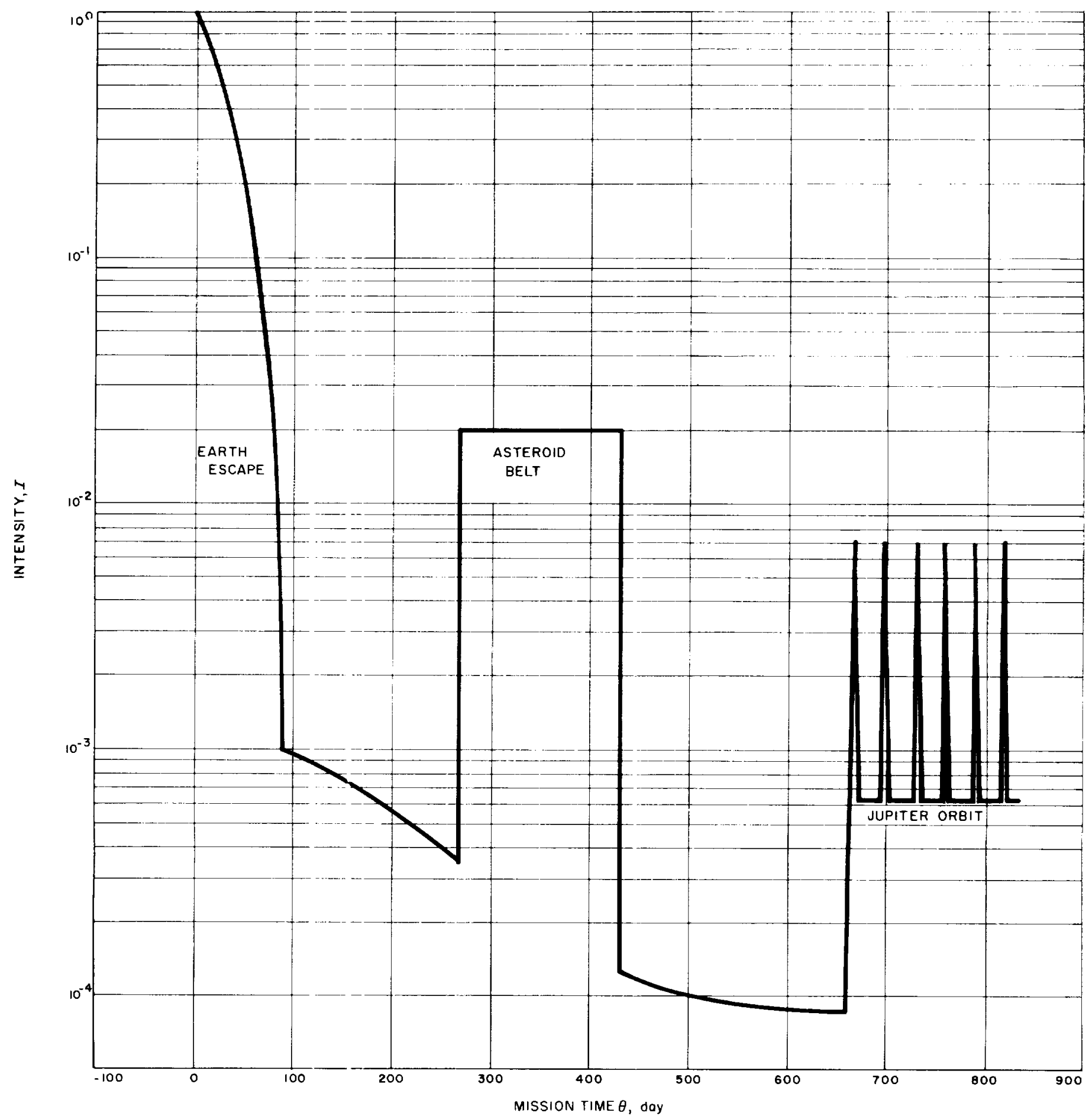

Fig. 6. Micrometeoroid flux intensity profile for a Jupiter orbiter mission 
titanium, however, as there are still a number of unanswered fabrication problems associated with beryllium.

Another item for consideration is the integral nuclear reactor-boiler concept (Ref. 8). In this design, all external piping and valves of the primary loop are eliminated, and the boiler is completely integrated with the reactor, all of which results in a simple and compact unit that lends itself to case of startup and control.

In such an arrangement in which the boiler is located adjacent to the reactor, the potassium working fluid will be exposed to the intense neutron radiation emanating from the reactor and, in turn, will become activated. As this fluid flows through the power conversion equipment, and especially the primary radiators and subcoolers, the activated fluid will decay and contribute to the total dose at the space cruiser payload. This problem has been investigated and results of the study indicate that the dose at the payload from the activated fluid is probably of minor significance.

Other shielding studies have been made to determine the effect that changes of various space cruiser parameters have upon the shield weight. Three parameters of interest are (1) the distance between the reactor core and the space cruiser payload, (2) the outer radius of the payload, and (3) the allowable dosage at the payload.

Employing the space cruiser of Fig. 1 as a model, typical results indicate that if the distance (parameter 1) were increased by $10 \mathrm{ft}$, the direct-neutron-shadow shield weight would decrease about $20 \%$ from a nominal value. Similarly, for a decrease of $10 \mathrm{ft}$, the shield weight would increase approximately $30 \%$. In the case of parameter 2 it has been found, for example, that if the payload outer radius were to be varied $: \pm 1 \mathrm{ft}$ from a nominal radius, the shield weight might vary by as much as $\pm 15 \%$ from the nominal shield weight. For parameter 3 , a change in allowable dosage at the payload from $10^{13} \mathrm{n} / \mathrm{cm}^{2}$ to $10^{14} \mathrm{n} / \mathrm{cm}^{2}$ can decrease the shicld weight by as much as $30 \%$.

From studies of this type, it can be concluded that within the limitations of the booster shroud constraints, a fairly long spacecraft with a small diameter payload region is desirable. One can also readily see why it is necessary to work toward the development of nuclear radiation-resistant electronic components. 


\section{PROPULSION SYSTEM PARAMETRIC STUDIES}

The results of detailed studies of the nominal 500-kwe power-system components discussed in Sections III $\mathrm{A}$ and $B$ indicate that it is feasible to clesign a turbogeneration system for 20,000 )-hr operation having a specific weight of about 13 to $14 \mathrm{lb} / \mathrm{kwe}$. The achievable specific weight is very sensitive, however, to the integration of the components into a total propulsion system and a complete spacecraft. The physical placement and resulting spacecraft dimensions have a particularly strong influence upon shield weight (Sectim III C), which in turn contributes a significant amount to total propulsion system weight.

Parametric studies of propulsion : vistem weight about the nominal conditions of $500 \mathrm{kwe}$ and $18 \mathrm{lb} / \mathrm{kwe}$ (corresponding to a powerplant specific weight of $14 \mathrm{lb} / \mathrm{kwe}$ ) differentiate those parameters which are of major importance from those which are mor in determining total system weight. Figure 7 shows a plot of propulsion

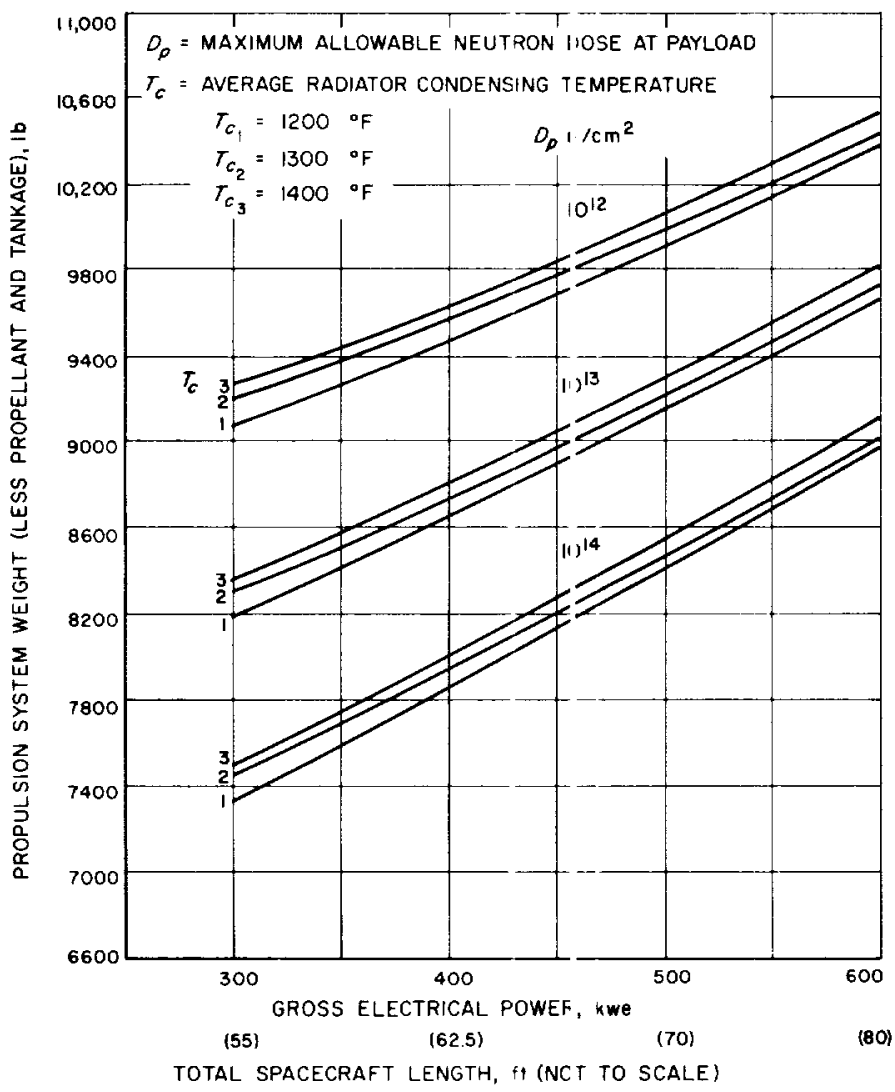

Fig. 7. Propulsion system weight vs. gross electrical power system weight (less propellant and tankage) vs. gross electrical power for three primary radiator condensing temperatures and three allowable nuclear radiation dosages at the spacecraft payload. The curves shown represent a variation of powerplant operating parameters, assuming the basic class of powerplant design presented in Section III. The general arrangement of components shown in Fig. 1 was maintained with the over-all length, shield thickness and radiator arcas varied as required by each selected operating point. The spacecraft width and booster shroud angle were kept constant, however.

From Fig. 7, it is apparent that the selection of allowable nuclear radiation dosage at the payload has a major effect upon total propulsion system weight. The nuclear shield weight is obviously a major contribution to total propulsion system weight as shown previously in Table 2 and in the discussion of Section III C.

The influence of primary radiator condensing temperature over the range of 1200 to $1400^{\circ} \mathrm{F}$ indicates that the selection of condensing temperature has a relatively minor effect upon total propulsion system weight. It is interesting to note that in this case the higher condensing temperature indicates a greater system weight. Analysis shows that allowing higher condensing temperatures results in lighter radiators (since the condensing tube djameter becomes smaller), but the total primary radiator area remains almost constant. For cach condensing temperature, a mass-optimized tube-fin geometry, utilizing a constant temperature gradient fin configuration, is employed and the turbine inlet temperature is assumed to be fixed at a maximum level of $1900^{\circ} \mathrm{F}$ as dictated by materials teclinology. The higher radiator rejection efficiency at the higher temperature is offset by the requirement for greater total heat rejection resulting from a reduction in powerplant cycle efficiency. It is the reduction in cycle efficiency that makes the propulsion system weight increase through the requirement for a higher-output reactor. As the condensing temperature rises, the reactor, boiler and shield weights increase significantly. Conversely as the condensing temperature decreases, the total propulsion system weight drops until it attains a minimum weight at a condensing temperature of around 1150 to $1175^{\circ} \mathrm{F}$. For this system, one can conclude that a near-optimum condensing temperature of around $1200 \mathrm{~F}$ is a satisfactory selection. The fact that total propulsion system weight is relatively insensitive 
to condensing temperature, of course, gives the nuclear powerplant designer some latitude in tailoring his system to meet materials technology constraints.

As gross electrical power is varied (illustrated in Fig. 7), the total spacecraft length is allowed to vary with the requirement of heat rejection area. The length corresponding to the various power levels is also shown in Fig. 7.

In Fig. 8, the propulsion system specific weights corresponding to the weights shown in Fig. 7 are plotted for the various levels of gross electrical power. From this plot, one can see the manner in which specific weight decreases as one goes to higher power levels. Although this trend has been postulated many times before, the numerical values shown in Fig. 8 give a reasonably accurate picture of the actual magnitudes for a "hard design" of the type described in this Report.

Employing this specific weight information in a study of effects of gross power level upon mission performance, one may arrive at the plot shown in Fig. 9. In this case, a total flight time of 750 days has been selected and main-

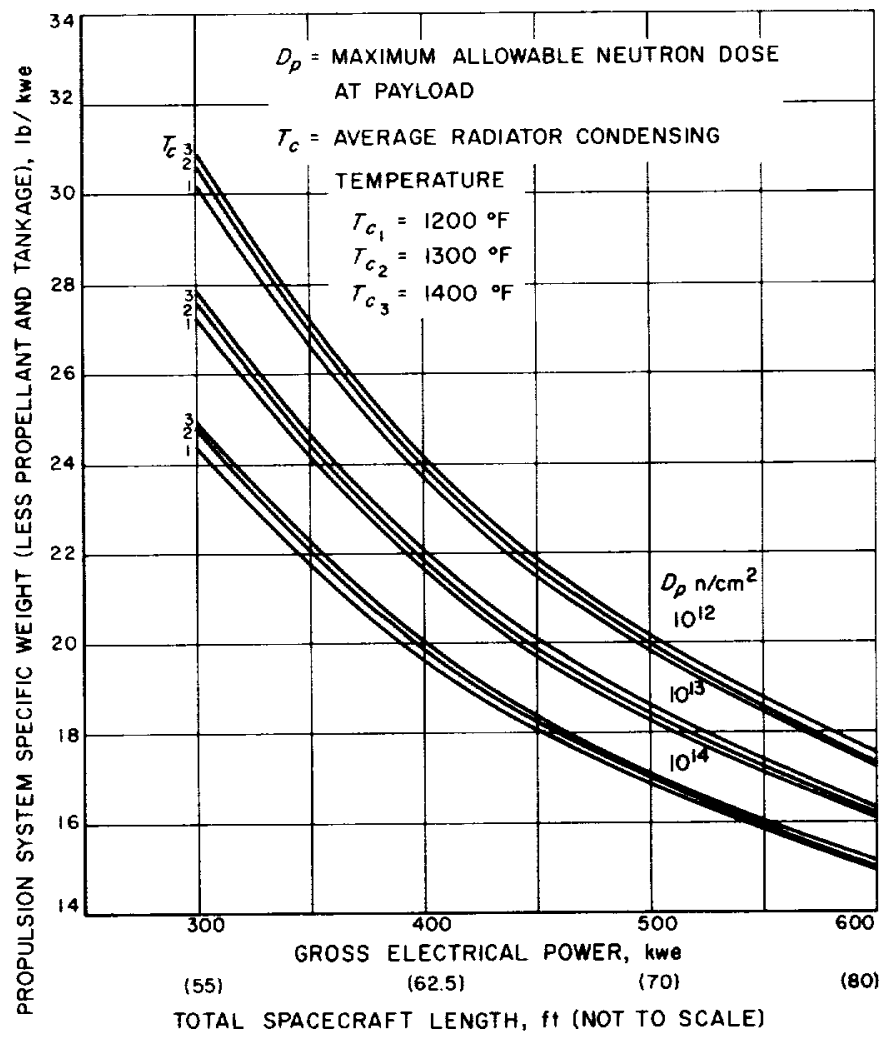

Fig. 8. Propulsion system specific weight vs. gross electrical power tained at each power level. As shown earlier in this Report, this allows about two orbits around Jupiter with power available from the powerplant for scientific measurements if one assumes a total lifetime of $20,000 \mathrm{hr}$. In determining the mission performance capabilities, an appropriate amount of the gross electrical power is set aside for power conditioning losses and spacecraft utility with the remainder available for the ion motor. These latter numbers are also shown in Fig. 9. The net payload shown includes guidance and control, communications, structure, propellant tankage, engineering instrumentation and scientific payload. From this plot it is apparent that the payload varies only slightly over a fairly wide range of gross electrical output levels. In other words, the propulsion system designer has reasonable latitude in selecting the propulsion system operating point. This ability can be employed to aid him in meeting various other system constraints, for example, the requirement for reasonable total spacecraft length as constrained by booster considerations. For the system described in this Report, a total length of about $70 \mathrm{ft}$ was selected as the maximum length allowed by the booster. This resulted in a power level of approximately $500 \mathrm{kwe}$. If $65 \mathrm{ft}$ were the maximum length, a lower power level could be employed with only a small decrease in payload.

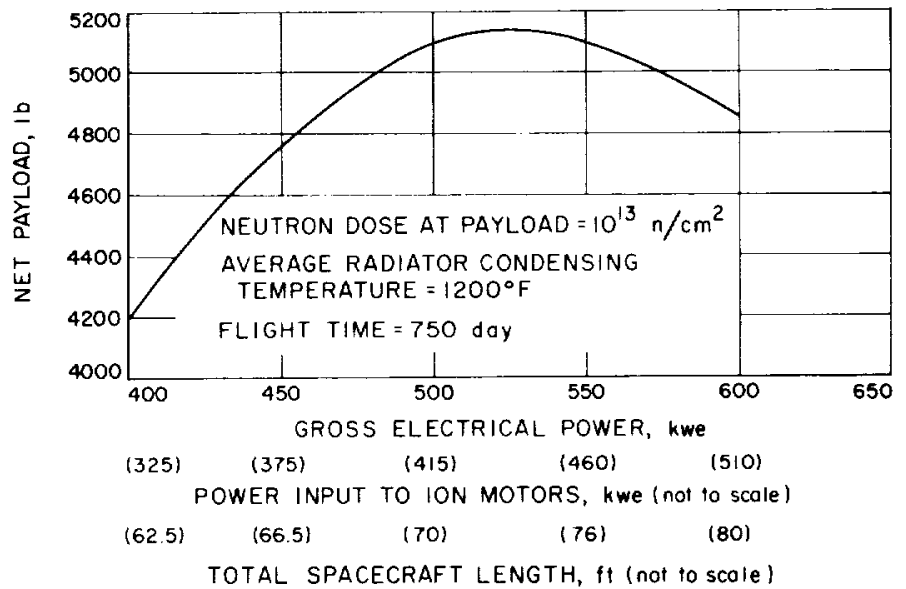

Fig. 9. Net payload vs. gross electrical power

Thus, at 500 kwe and $70 \mathrm{ft}$ length a spacecraft could be designed requiring no folding radiator surfaces and employing a powerplant having a weight of approximately $7100 \mathrm{lb}$, which could be boosted by a Saturn $1-B$ class booster. Such a 500-kwe system can be considered to be a "natural" fit for the Saturn vehicle.

In addition to the tradeoff capabilities just discussed, there is further flexibility in that if powerplants as light 
as $14 \mathrm{lb} / \mathrm{kwe}$ (18 lb/kwe propulsion system) were unavailable the spacecraft designer could still achieve a useful mission at a somewhat highe specific weight by either delivering less net payload (not necessarily less scientific payload if one can lighten other systems) or the same payload in a longer time period.

\section{v. CONCLUSIONS}

The spacecraft concept described in this Report represents a logical follow-on to existing or planned chemicalspacecraft probes for planetary exploration. Those who accept this fact, that nuclear-electic systems will be required to continue the national pro gram for the orderly exploration of space, should see the overwhelming economic advantage of employing at noclest single spacecraft design with a modest booster system for the maximum number of planetary missions.

While it is true that specific detids, such as system power level, spacecraft length, arrangement of radiator tubes and of ion motor modules, ete, could be argued, it is an indisputable fact that a syste $n$ having nominally the operating parameters shown is a much more realistic approach and attainable goal for early space exploration than one attempting to utilize a mutimegawatt electric unit on a needlessly large and expen ive booster system.

Larger units employing Nova-class or nuclear boosters will, of course, eventually be requir el for sophisticated interplanetary manned flight, but the:e must be preceded by more modest, unmanned explorat ory probes designed to establish the initial information concerning the interplanetary and planetary enviromment.

Those who do not admit the need for nuclear-electric system development for high-energy missions should perhaps bear in mind the alternatives: the use of exceedingly large, expensive chemical and nuclear-rocket boosters delivering significantly less payload in longer trip times. It is interesting to note that such alternate systems will require a nuclear-electric power system for supplying communication and spacecraft utility power even if electric propulsion is not utilized.

Lifetime goals for nuclear-electric systems of 10,000 to $20,000 \mathrm{hr}$ are, of course, a major challenge, but even longer lifetimes would be needed for comparable chemical Hights. Fortunately, there are several far-sighted efforts under way in this country which are helping to develop the technology which will be required in the useful ipplication of nuclear-electric systems for space exploration. It is hoped that the results presented in this Report can help guide such rescarch efforts toward goals of greatest utility for actual space missions. 


\section{REFERENCES}

1. Edelbaum, T. N., "Mission Capabilities of Ion Engines," UAC Report No. R-1297-9, Contract NAS5-935, Phase II-Final Report, March 1962.

2. Beale, R. J., and Speiser, E. W., "A Nuclear-Electric Space Bus for Planetary Landing Missions," Technical Report No. 32-231, Jet Propulsion Laboratory, Pasadena, California, May 1, 1962.

3. Speiser, E. W., "Performance of Nuclear-Electric Propulsion Systems in Space Exploration," Technical Report No. 32-159, Jet Propulsion Laboratory, Pasadena, California, December 15, 1961.

4. Stearns, J. W., "Electric Propulsion Requirements for Planetary and Interplanetary Spacecraft," Technical Report No. 32-403, Jet Propulsion Laboratory, Pasadena, California. (To be published.)

5. Hayes, R. J., Hoffman, M. A. and Stuhlinger, E., "The Manned Electric Rocket Challenge," Preprint No. 2222-61, ARS Space Flight Report to the Nation, New York, October 9-15, 1961.

6. Melbourne, W. G. and Sauer, C. G., "Optimum Thrust Programs for Power-Limited Propulsion Systems," Technical Report No. 32-118, Jet Propulsion Laboratory, Pasadena, California, June 15, 1961.

7. Volkoff, J. J., "Protection Requirements for the Resistance of Meteorite Penetration of Interplanetary Spacecraft Systems," Technical Report No. 32-410, Jet Propulsion Laboratory, Pasadena, California (to be published).

8. Davis, J. P., "A Nuclear Reactor Concept for Electric Propulsion Application," Technical Report No. 32-385, Jet Propulsion Laboratory, Pasadena, California, March 4, 1963. 


\section{ACKNOWLEDGEMENTS}

The authors wish to express their gratitude to the mombers of the Advanced Propulsion Engineering Section for their invaluable assistance in performing the system analysis studies discussed in this Report, and to Mr. Car E. Berglund for his contribution in developing the space cruiscr co figuration. 